\title{
PERIPHERAL AVMS PRE-OPERATIVE EMBOLIZATION USING PLUG AND PUSH TECHNIQUE WITH LOW-DENSITY NBCA/LIPIODOL CAN BE USED IN HIGH-FLOW FEEDING ARTERIES AT HUE CENTRAL HOSPITAL, VIETNAM: A CASE REPORT \\ Ho Anh Binh, Nguyen Ngoc Son, Vu Huynh Nguyen, Duc Dung Nguyen, Anh Khoa Phan Department of Emergency and Cardiology Interventional, Hue Central Hospital
}

DOI: $10.47122 / v j d e .2020 .40 .6$

\begin{abstract}
S
Purpose: The aim of this study was to report our experience in one casepreoperative embolization of high-flow peripheral arteriovenous malformations (AVMs) using plug and push technique with low-density NBCA/LIPIODOL. Case presentation: A patient 26 years old man hospitalized at Hue Central Hospital, Vietnam with big pulsatile mass at right femoral above the knee. Doppler ultrasound showed a mass with high systolic and diastolic velocities. Patient felt discomfort and he has a desire to resolve this condition. Angiogram showed a large and high-flow arteriovenous malformation type IV according to Yakes classification. A multidisciplinary discussion was required between surgeon and interventionist because of the high risk of inoperative hemorrhage. Patient was treated with low-density NBCA/LIPIODOL $12.5 \%$ embolic agents by transarterial approach using plug and push technique before surgical excision. Results: Technical success was achieved in this patient. Complete devascularization was obtained and surgical excision was performed at 4 days after embolization procedure. Non-target NBCA/LIPIODOL embolization was not observed. Conclusions: Embolization using plug and push technique with low-density NBCA/LIPIODOL is an promising and interesting option for management of peripheral high-flow AVMs either preoperatively or as a single treatment.
\end{abstract}

Keywords: embolization, high-flow peripheral arteriovenous malformations (AVMs), plug and push technique, low-density NBCA/LIPIODOL.

Main correspondence: Ho Anh Binh

Submission date: $7^{\text {th }}$ May 2020

Revised date: $18^{\text {th }}$ May 2020

Acceptance date: $28^{\text {th }}$ June 2020

Email: drhoanhbinh@gmail.com

\section{INTRODUCTION}

Arteriovenous malformations (AVMs) are unusual communications between arteries and veins that result from angiogenesis disorders, without the interposition of the capillary system. These shunts call nidus, in most of cases, are multiple and are configured as a mass of intrinsically related vessels[1].

Endovascular embolization has been suggested as a treatment option since the early 1970s. Its aim is either palliative in symptomatic patients with impossible surgical resection or to minimize intra-operative hemorrhage and facilitate complete resection [2]. The ethylene vinyl alcohol copolymer (EVOH: Onyx; ev3-Covidien, Irvine, CA, USA) is a non-adhesive liquid embolic agent that has been used since the early 1990s [3]. N-butyl cyanoacrylate (NBCA) is a cyanoacrylate that is commonly used for medical care, and the closure of skin wounds with NBCA has been found to promote hemostasis. NBCA-based embolotherapy can be used to treat vascular malformations, acute hemorrhaging, tumors, and venous diseases. NBCA is mixed with Lipiodol to make it radiopaque and to adjust its polymerization time. are various technical aspects to 
performing NBCA-based embolotherapy safely, it should be carried out by, or with the assistance of, proficient interventional radiologists [4].

\section{EMBOLIZATION TECHNIQUE}

Patients underwent diagnostic angiography via a percutaneous transarterial approach. The embolization was occured at a second session after the diagnostic angiography because a second multidisciplinary discussion was required. The procedure was performed by right femoral puncture with antegrade approach and introduction of a $10 \mathrm{~cm}-6 \mathrm{Fr}$ sheath to allow perprocedure angiograms with the microcatheter in place. Amicrocatheter Renegade STC18 was used to perform selective catheterization.

The microcatheter was placed as near as possible to the nidus. According to operator judgment depending on microcatheter tip position in relation to the nidus and the flow within the AVM, NBCA/Lipiodol type to be used was decided. Lower concentration (12.5\%: the ratio of the concentration is between $0.5 \mathrm{ml} / 0.5 \mathrm{mg}$ NBCA and $3.5 \mathrm{ml}$ Lipiodol) of the copolymer was preferred in high-flow lesions with microcatheter tip was very close or in the nidus to avoid the risk of pulmonary migration.
Further NBCA/Lipiodol injections were performed under serial glue roadmap imaging.

We use plug and push technique for injection. The injection was maintained and repeated until the feeding arteries and the nidus were completely occluded or until major reflux towards the parent artery was seen. When reflux was noted along the microcatheter in the catheterized feeder, injection was stopped and repeated few minutes later in order to allow the proximal NBCA/Lipiodol cast to solidify and thus distal penetration of NBCA/Lipiodol in the nidus could be obtained. If reflux persisted catheterization of another feeding branch was performed and injections repeated in order to occlude consecutively all the feeding branches and the nidus. Completion angiogram was realized through the guiding catheter with the microcatheter in place to evaluate the degree of devascularization. Guiding catheter appearance in the ostial of parent artery is to reduce the distal low-limb occlusion due to liquid embolic agent when we retrieval the microcatheter.

Complete technical success was defined as absent flow through the nidus with disappearance of the early opacification of draining veins.

\section{RESULTS}

At the beginning, we did the angiogram with guiding catheter 5F JR. The AVM has 3-4 main parent arteries (Figure 1).

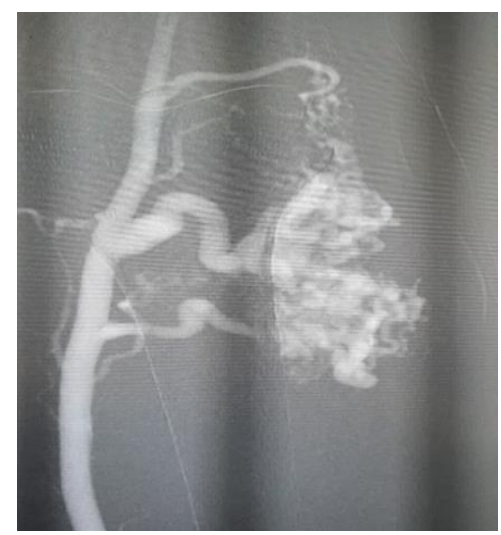

Figure 1. An AVM under angiogram of 26 y/o man. Type IV AVM follow by Yakes classification[10]. 
We performed the embolization procedure in this patient with 2 sessions. Patient had undergone 1 embolization (Figure 2) and after 4 days, 1 surgical excision of a large femoral AVM (Figure 3). The mean volume of injected NBCA/Lipiodol was 15-20ml. Post-embolization angiogram revealed total occlusion. Patient was operated at 4 days after the embolization. Clinical symptoms is medium pain and swelling still exist after embolization 24 hours, these symptoms decrease gradually and disappear during 4 days. No long-term peripheral circulation or pulmonary deficitwas noted during the period of follow-up. No changing of skin color after embolization and surgery and at the time 10 days after hospital discharge.

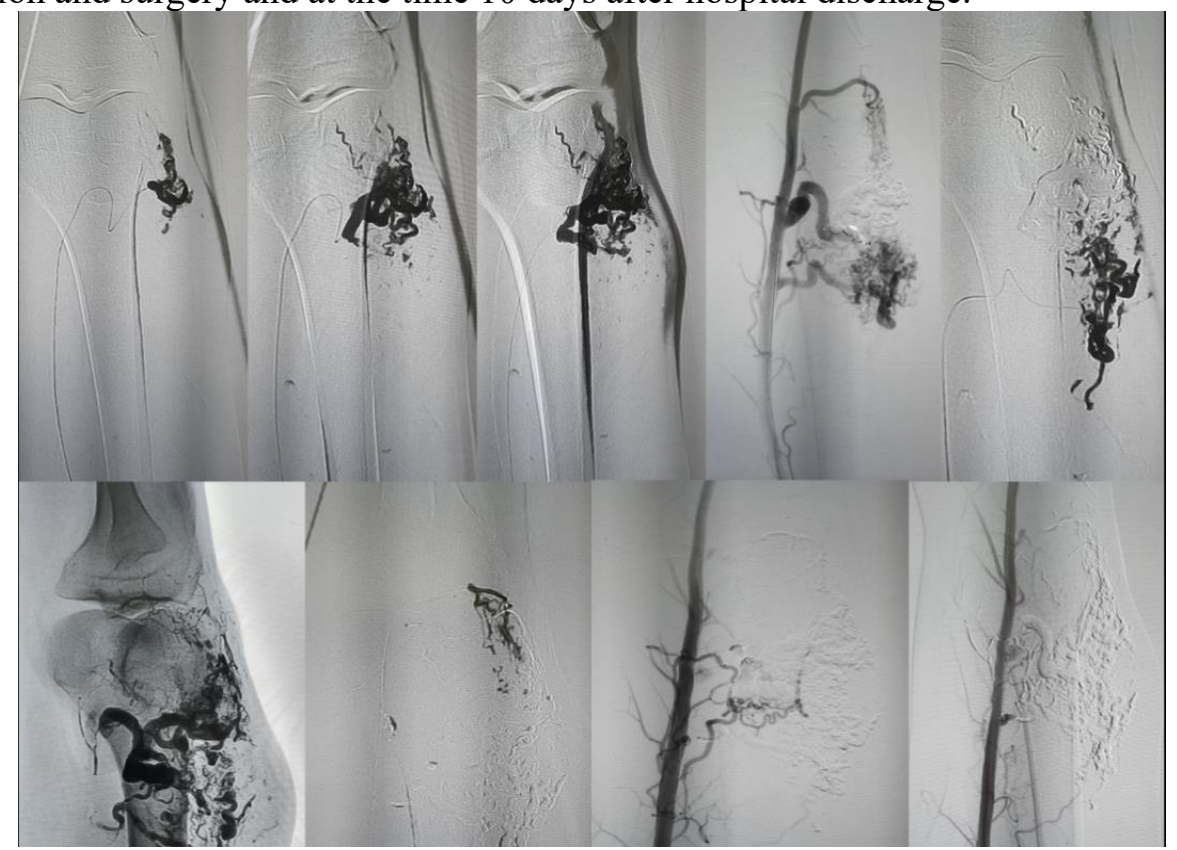

Figure 2. The process of AVM embolization of $26 \mathrm{y} / \mathrm{o}$ patient through antegradely femoral approach. Microcatheter was located as close as possible to the nidus. Low-density NBCA/Lipiodol was push into the nidus by plug and push technique. Three main parent artery was occluded. After embolization, AVM was totally occluded.

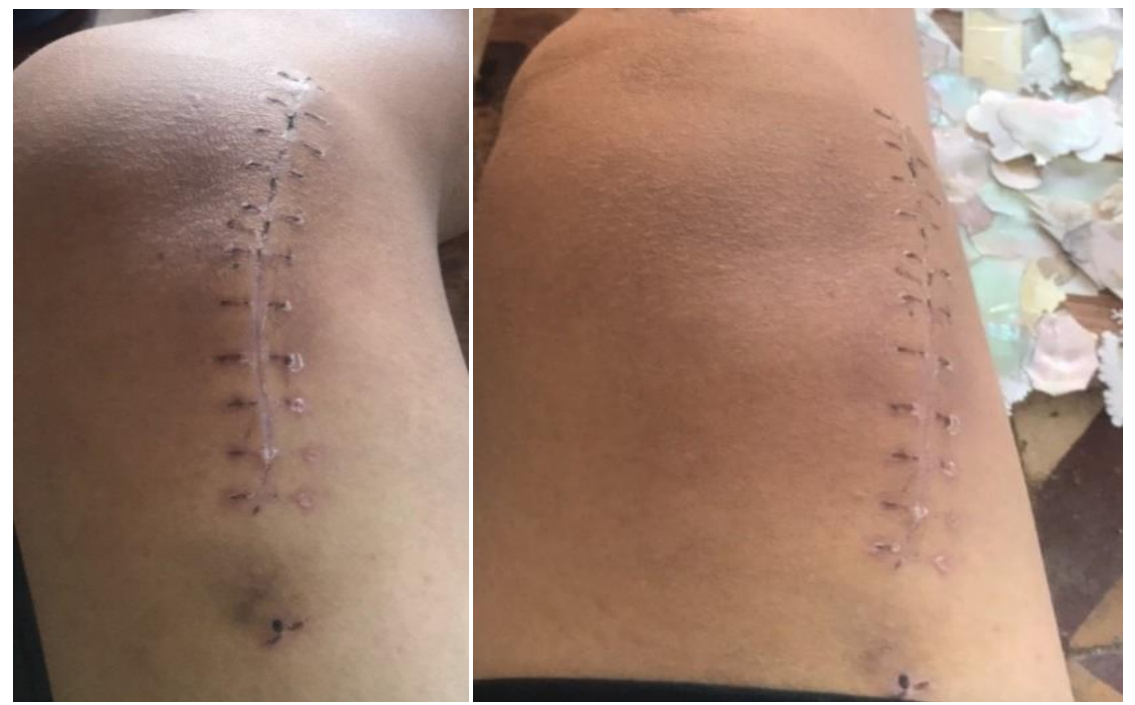

Figure 3. Scar after surgical excision of $26 \mathrm{y} / \mathrm{o}$ patient 


\section{DISCUSSION}

Endovascular transcatheter embolization of pAVMs followed or not by surgical excision is a validated therapeutic option. It is frequent that multiple embolization sessions are necessary [5-9].

In our report, we examined the type IV arteriovenous malformation according to Yakes classification. Yakes developed a new classification (Figure 1) of the angioarchitecture of these lesions. The AVM Classification System is used to determine endovascular approaches and the embolic agents that will be successful to ablate these AVMs [10]. The classification of Yakes included lesions that by ISSVA classification are grouped as arteriovenous fistulas (AVFs) and not as AVMs (according to ISSVA Classification from 2018 [11]). Then NBCA was used because of these benefits and the patient could accept easier for low-cost price, especially in Vietnam, a developing country.

The tissue-adhesive NBCA is one of the preferred agents currently available for AVMs embolization. Precise use of NBCA and safe embolization is almost impossible due to unpredictable behavior when it comes in contact with blood (reflux, migration or immediate polymerization).Complications such as off-target embolization and catheter gluing can occur [12,13]. In addition, after injection of NBCA, the microcatheter should be removed immediately to avoid gluing the catheter to the vessel wall, which may require restarting a difficult catheterization in case of incomplete embolization [14]. In order to avoid these potential complications, some authors proposed the use of diluted NBCA, which seems have a similar tissue response to that of the high-concentration form [15].

In our report, we used guiding catheter located at the ostial of parent artery which aim to avoid the distal peripheral ischemia due to embolic agent after removing immediately microcatheter. Besides, we diluted $0.5 \mathrm{ml} / 0.5 \mathrm{mg}$ NBCA with $3.5 \mathrm{ml}$ Lipiodol at the ratio $1: 7$, respestively. With this concentration $(12,5 \%)$, NBCA can be used to occlude entire the nidus.

Some systemic and/or local reactions have been reported which is associated with vascular embolization using NBCA, such as nausea/vomiting, high fever, and regional pain [16-22].

In our report, patient just developed nonspecific pain during the procedure which responded well to simple analgesia medication.

Our study is limited by one case report. Relatively good results presented may be based by the experience of the operators with multidisciplinary meeting. Embolization was only performed if a relatively high rate of technical success was predicted. This highlights the importance of multidisciplinary approach when managing this type of patients.

In conclusion, transcatheter embolization usingplug and push technique with diluted NBCA/Lipiodol is an acceptable treatment option at stopping hemorrhaging and controlling vascular disease, especially in high-flow AVMs followed or not by surgical excision. Interventionist should have a good knowledge of the indications and complications associated with NBCA use and experience techniquebefore practicing in clinical situation.

\section{REFERENCES}

1. Carnevale FC (2017) Treatment of interventional radiology and endovascular surgery. Thieme Revinter Publications LTDA. Koizumi T, Shiraishi T, Hagihara N, Tabuchi K, Hayashi T, et al. (2002) Expression of vascular endothelial growth factors and their receptors in and around intracranial arteriovenous malformations. Neurosurg 50: $117-126$

2. Jacobowitz GR, Rosen RJ, Rockman CB, et al. Transcatheter embolization of complex pelvic vascular malformations: Results and long-term follow-up. J Vasc Surg 2001;33:51-5.

3. Terada T, Nakamura Y, Nakai K, et al. 
Embolization of arteriovenous malformations with peripheral aneurysms using ethylene vinyl alcohol copolymer. Report of three cases. J Neurosurg 1991;75:655-60.

4. Yoshito T et al. Guidelines for the use of NBCA in vascular embolization devised by the Committee of Practice Guidelines of the Japanese Society of Interventional Radiology (CGJSIR). Japan Radiological Society 2014;1-4.

5. Castaneda F, Goodwin SC, Swischuk JL, et al. Treatment of pelvic arteriovenous malformations with ethylene vinyl alcohol copolymer (Onyx). J Vasc Interv Radiol 2002;13:513-6.

6. Clarenc, on F, Blanc R, Lin CJ, et al. Combined endovascular and surgical approach for the treatment of palpebral arteriovenous malformations: experience of a single center. AJNR Am J Neuroradiol 2012;33:148-53.

7. Do YS, Yakes WF, Shin SW, et al. Ethanol embolization of arteriovenous malformations: interim results. Radiology 2005;235:674-82.

8. Tan KT, Simons ME, Rajan DK, Terbrugge K. Peripheral high-flow arteriovenous vascular malformations: a single-center experience. J Vasc Interv Radiol 2004;15:1071-80.

9. Lee B-B, Do YS, Yakes W, et al. Management of arteriovenous malformations: a multidisciplinary approach. J Vasc Surg 2004;39:590600.

10. Frey S, Cantieni T, Vuillemin N, Haine A, Kammer R, et al. (2018) Angioarchitecture and hemodynamics of microvascular arteriovenous malformations. PloS one 13: e0203368.

11. Cho SK, Do YS, Shin SW, Kim DI, Kim YW, et al. (2006) Arteriovenous malformations of the body and extremities: analysis of therapeutic outcomes and approaches according to a modified angiographic classification. J Endovasc Ther 13: 527-538.
12. Debrun GM, Aletich VA, Shownkeen H, Ausman J. Glued catheters during embolisation of brain AVMs with acrylic glue. Interv Neuroradiol 1997;3:13-9.

13. Niimi $Y$, Berenstein A, Setton A. Complications and their management during NBCA embolization of craniospinal lesions. Interv Neuroradiol 2003;9:157-64.

14. Pollak JS, White Jr RI. The use of cyanoacrylate adhesives in peripheral embolization. J Vasc Interv Radiol 2001;12:907-13.

15. Sadato A, Wakhloo AK, Hopkins LN. Effects of a mixture of a low concentration of n-butylcyanoacrylate and ethiodol on tissue reactions and the permanence of arterial occlusion after embolization. Neurosurgery 2000;47:1197-203.

16. Denys A, Lacombe C, Schneider F, Madoff DC, Doenz F, Qanadli SD, et al. Portal vein embolization with N-butyl cyanoacrylate before partial hepatectomy in patients with hepatocellular carcinoma and underlying cirrhosis or advanced fibrosis. JVIR. 2005;16(12):1667-74.

17. Inaba Y, Arai Y, Matsueda K, Takeuchi Y, Aramaki T. Right gastric artery embolization to prevent acute gastric mucosal lesions in patients undergoing repeat hepatic arterial infusion chemotherapy. JVIR. 2001;12(8):95763.

18. Jackson JE, Mansfield AO, Allison DJ. Treatment of high-flowvascular malformations by venous embolization aided by flowocclusion techniques. Cardiovasc Intervent Radiol.1996;19(5):323-8.

19. Liu D, Ma XC. Clinical study of embolization of arteriovenous malformation in the oral and maxillofacial region. Chin J Dent Res. 2000;3(3):63-70.

20. Pelz DM, Lownie SP, Fox AJ, Hutton LC. Symptomatic pulmonary complications from liquid acrylate 
embolization of brain arteriovenous malformations. Am J Neuroradiol. 1995;16(1):19-26.

21. Pollak JS, White RI Jr. The use of cyanoacrylate adhesives in peripheral embolization. JVIR. 2001;12(8):907-13.

22. Winkelbauer FW, Niederle B,
Pietschmann F, Thurnher S, Wildling R, Prokesch R, et al. Hepatic artery embolotherapy of hepatic metastases from carcinoid tumors: value of using a mixture of cyanoacrylate and ethiodized oil. AJR Am J Roentgenol. 1995;165(2):323-7. 